\title{
Correction to: Visualization of small visceral arteries on abdominal CT angiography using ultra-high-resolution CT scanner
}

\author{
Kazuya Ogawa ${ }^{1} \cdot$ Hiromitsu Onishi $^{1}$ (1) $\cdot$ Masatoshi Hori ${ }^{1} \cdot$ Atsushi Nakamoto $^{1} \cdot$ Takashi Ota $^{1} \cdot$ Hideyuki Fukui $^{1}$. \\ Mitsuaki Tatsumi ${ }^{1} \cdot$ Yukihiro Enchi $^{2} \cdot \mathrm{Kazuhiko} \mathrm{Sato}^{2} \cdot \mathrm{Koki}$ Kaketaka $^{1} \cdot$ Noriyuki Tomiyama $^{1}$
}

Published online: 12 June 2021

(c) Japan Radiological Society 2021

Correction to: Japanese Journal of Radiology

https://doi.org/10.1007/s11604-021-01124-6

In the original publication Fig. 3 a has been included twice in place of Fig. 3b. The corrected Fig. 3 is given in this Correction.

The original publication has been corrected.

Publisher's Note Springer Nature remains neutral with regard to jurisdictional claims in published maps and institutional affiliations.

The original article can be found online at https://doi.org/10.1007/ s11604-021-01124-6.

Hiromitsu Onishi

h-onishi@ radiol.med.osaka-u.ac.jp

1 Department of Diagnostic and Interventional Radiology,

Osaka University Graduate School of Medicine, 2-2

Yamadaoka, Suita, Osaka 565-0871, Japan

2 Division of Radiology, Department of Medical Technology,

Osaka University Hospital, Suita, Japan 
Fig. 3 Partial MIP image of CTA of SMA branches. a : HR CTA with a matrix of $1024 \times 1024$ more accurately delineated the marginal arteries and vasa recta than $(\mathbf{b})$ : NR CTA with a matrix of $512 \times 512$. Profile curves of the small mesenteric artery of (c): HR CTA and $\mathbf{d}$ : NR CTA
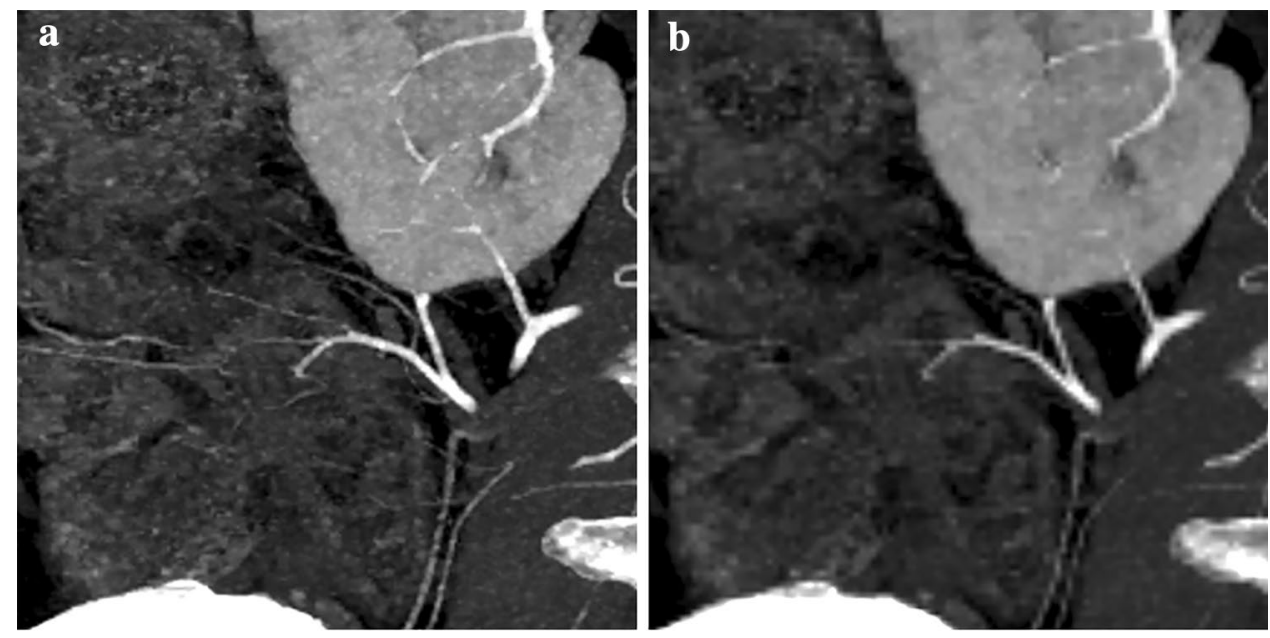

\section{c}

d
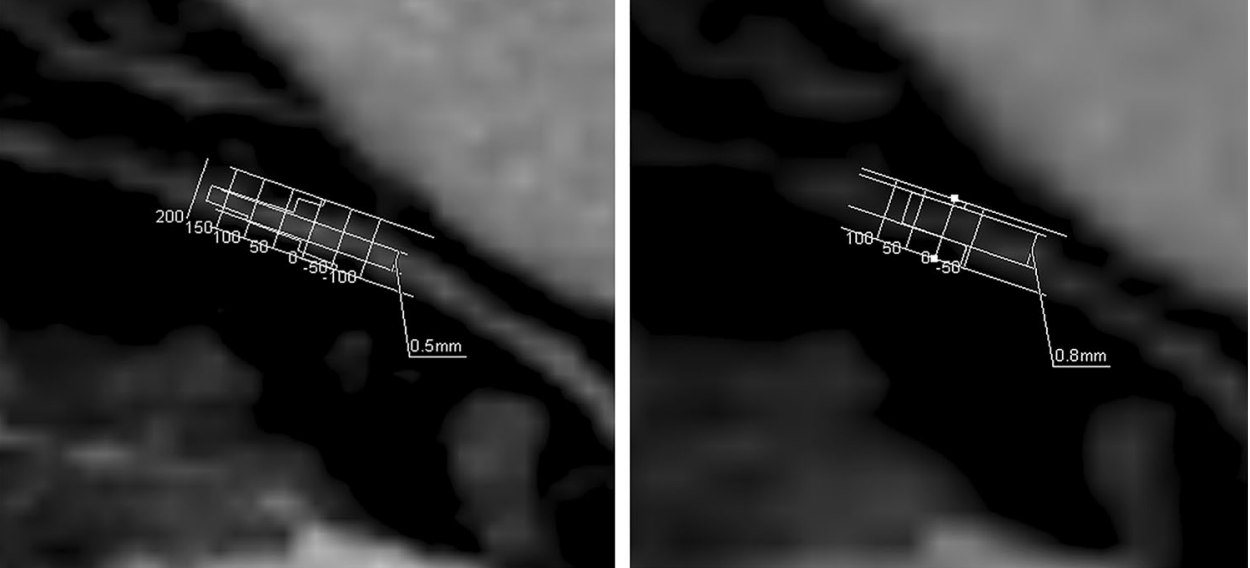